\title{
Investigation of Wear Behaviour and Mechanical Properties of Titanium Diboride Reinforced AMMC Composites
}

\author{
Madhan Prabhu Deva, ${ }^{1}$ A. Parthiban, ${ }^{2}$ B. Radha Krishnan, ${ }^{3}$ Adisu Haile, ${ }^{4}$ \\ and Wubishet Degife $\mathbb{1}^{4}$ \\ ${ }^{1}$ Mechanical Engineering, Vels Institute of Science Technology and Advanced Studies, Chennai, Tamilnadu, India \\ ${ }^{2}$ Mechanical Engineering, Vels Institute of Science Technology and Advanced Studies, Chennai, Tamilnadu, India \\ ${ }^{3}$ Mechanical Engineering, Nadar Saraswathi College of Engineering and Technology, Theni, Tamilnadu, India \\ ${ }^{4}$ Department of Mechanical Engineering, Wollo University, Kombolcha Institute of Technology, Ethiopia
}

Correspondence should be addressed to Wubishet Degife; wubesvictory@kiot.edu.et

Received 18 September 2021; Revised 19 November 2021; Accepted 5 December 2021; Published 1 February 2022

Academic Editor: Waleed Fekry Faris

Copyright (C) 2022 Madhan Prabhu Deva et al. This is an open access article distributed under the Creative Commons Attribution License, which permits unrestricted use, distribution, and reproduction in any medium, provided the original work is properly cited.

\begin{abstract}
The aluminium metal matrix composites (AMMCs) are preferred in automotive and aerospace industries for higher strength, weight ratio, good corrosion resistance, and also better tribological properties. This study proposed that the AA7075 alloy methodology was enhanced by stir casting with titanium diboride $\left(\mathrm{TiB}_{2}\right)$ particles at different percentages $(5,10$, and 15 wt. \%). The preheated titanium diboride powder is spread to the molten state AA7075 at $870^{\circ} \mathrm{C}$ to provide good weight resistance and delivery. The prepared composites are evaluated by wear analysis, tensile properties, hardness range, and microstructural behavior studies. Pin-on-disk and Rockwell hardness tester were used to analyze the wear behaviour and hardness level. The tensile strength and hardness have defined the strength of the proposed composite while the addition of $\mathrm{TiB}_{2}$ particles improves the hardness and tensile stress. The findings showed that adding $\mathrm{TiB}_{2}$ particles in the Al7075 matrix strengthened all properties compared to the Al7075 matrix. The scanning electron microscope and EDS were used to analyze the eroded surface and chemical composition of composites.
\end{abstract}

\section{Introduction}

The AMMCs have higher usage in the automotive and aerospace industries due to their enhanced strength and low wear. Enhanced mechanical and tribological characteristics of AMMCs are provided by adding reinforcements such as $\mathrm{Al}_{2} \mathrm{O}_{3}, \mathrm{SiC}, \mathrm{TiC}, \mathrm{TiB}_{2}, \mathrm{ZrO}_{2}$, and $\mathrm{B}_{4} \mathrm{C}$ [1]. The AMMCs were made by the infiltration, powder metallurgy process, compocasting, and stir-casting method [2]. Many researchers used a stir-casting method to make AMMCs because of the maximum metal yield range, lower particle damage, and cost-efficiency. $\mathrm{TiB}_{2}$ particles are highly stiff and hard and had better thermal stability range among the different ceramic strengthening particles.

The exothermic nature of the process, as well as the reduced oxidation, makes it a good candidate for wear- resistant composites [3]. Normally, the composites are made with oxide particles, carbide particles, boride particles, and nitride particles. While added, the ceramic particulate matter in different aluminium matrices significantly increased the matrix wear performance [4]. Matrix reinforcement fraction is the factor that influences the composite mechanical properties. The wear has been observed to be oxidative wear to a maximum of $800^{\circ} \mathrm{C}$, and the oxidative wear has been found to dominate the wearing rate at higher temperatures. Certain scientists have found that the inhomogeneous distribution of reinforcement particles on a molten matrix results in low weight and low surface tension [5]. Preheating treatment is used to absorb gas and remove humidity and utilize any sort of surface protection, and inert gas-atmospheric alloying elements will improve the properties of the composites [6]. The particulate injection 
avoided or minimised agglomeration and particulate clusters and enhanced the homogeneous atmosphere and distribution. A few researchers have prepared AA7075- $\mathrm{TiB}_{2}$ composite and evaluated the mechanical properties. The AA7075- $\mathrm{TiB}_{2}$ composites were synthesized by the stircasting method with different percentages of $\mathrm{TiB}_{2}(5 \%, 10 \%$, and $15 \%$ wt.\%), and then the quality of the composites was inspected by tribological characteristics. This paper investigated the tribological properties such as wear and microstructural characteristics of compounds AA7075- $\mathrm{TiB}_{2}$ and investigated mechanical properties such as hardness.

\section{Experimental Analysis}

AA7075 alloy has been preferred as a matrix material in this study, and the chemical composition is illustrated in Table 1. An in situ reaction supported various amounts of $\operatorname{TiB}_{2}(5,10$, and 15 wt.\%).

The small pieces of Al7075 alloy are used for the composite's synthesis process. The quantity of matrix to be melted is measured with an additional $25 \%$ of slag. The induction crucible furnace was used to melt the aluminium alloy 7075 for $20 \mathrm{~min}$ with a temperature range of $850^{\circ} \mathrm{C}$.

Meanwhile, $\mathrm{TiB}_{2}$ was preheated up to $500{ }^{\circ} \mathrm{C}$, and then, it was added uniformly into the furnace for avoiding agglomeration and clustering. The stirring process was carried out with the four-blade stirrer for 10 minutes at $500 \mathrm{rpm}$. Due to the stirring process, a vortex is formed [7].

The preheated $\mathrm{TiB}_{2}$ particles have been fed into the furnace at proper timing intervals through a hopper which is shown in Figure 1. Approximately $750^{\circ} \mathrm{C}$ was regulated with continuous stirring to produce a uniform mixture. The molding mixture is formed by refreshing the mold at room temperature into rods and plates as shown in Figure 2 [8].

Figure 3 shows the processing methodology for AMMC and evaluation methods. The hardness and tensile tests were carried out for prepared specimens based on the ASTM E384-11 and ASTM E08 standards [9]. In this paper, the ASTM G99 standard was used as shown in Table 2 followed by wear test analysis of $\mathrm{Al} 7075-\mathrm{TiB}_{2}$ composite. The surface morphological characteristics and microstructural views are analyzed to investigate how reinforced particles are mixing with matrix materials by using the scanning electron microscope (SEM) and energy dispersive spectroscopy (EDS) [10].

The components' weight was determined by density, and the theoretical densities have been obtained by the rule of mixture (ROM).

\section{Results and Discussions}

3.1. EDAX Testing. In Figures 4 to 6 , the EDAX graph showed the aluminium and titanium peak values showing the particulate content of the composites made $[11,12]$. The EDAX graph of $\mathrm{Al} 7075 / 5 \% \mathrm{TiB}_{2}, \mathrm{Al} 7075 / 10 \% \mathrm{TiB}_{2}$, and $\mathrm{Al} 7075 / 15 \% \mathrm{TiB}_{2}$ composites shown in figures indicates the presence of aluminium and titanium particles.

3.2. Impact of Reinforcement on Tensile Strength. The tensile load is applied to create large internal tensions that can cause the material to break if they exceed its strength [13].
TABLE 1: Chemical constitutions of Al7075 alloy.

\begin{tabular}{lc}
\hline Constituents & Contribution \\
\hline $\mathrm{Al}$ & 90.60 \\
$\mathrm{Si}$ & 0.05 \\
$\mathrm{Fe}$ & 0.1 \\
$\mathrm{Cu}$ & 1.6 \\
$\mathrm{Mn}$ & 0.05 \\
$\mathrm{Mg}$ & 2.31 \\
$\mathrm{Cr}$ & 0.11 \\
$\mathrm{Zn}$ & 5.12 \\
$\mathrm{Ti}$ & 0.05 \\
$\mathrm{Ti}+\mathrm{Zn}$ & 0.01 \\
\hline
\end{tabular}

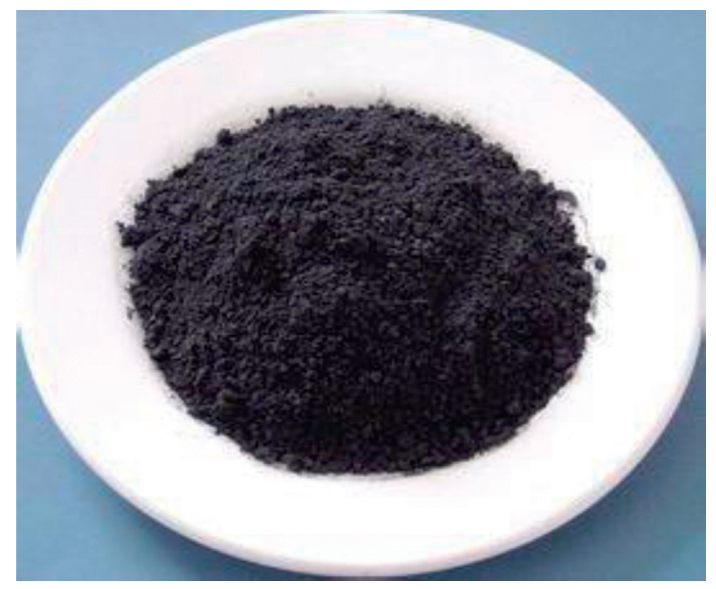

Figure 1: Titanium diboride.

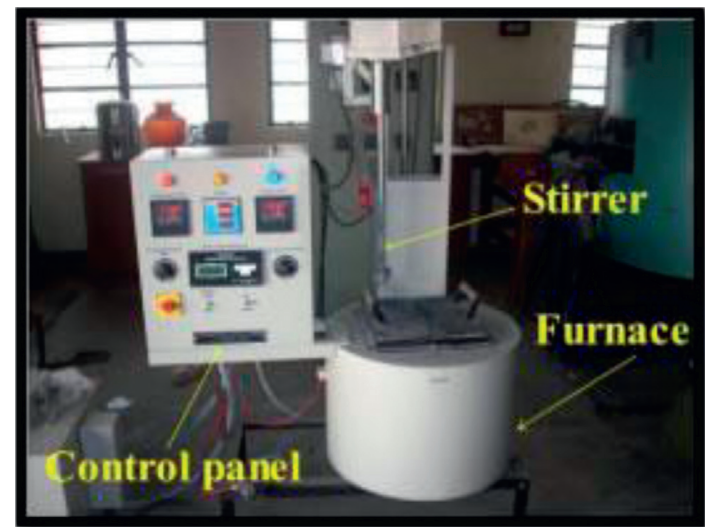

FIgURE 2: Bottom pouring stir casting.

Reinforcement particle bonding will be the major focus of the internal stress distribution. The tensile strength of Al7075 composites is enhanced when the percentage of $\mathrm{TiB}_{2}$ is increased, as shown in Figure 7.

Figure 7 shows that while adding $\mathrm{TiB}_{2}$ particles, the tensile strength increases proportionally, increasing $242 \mathrm{MPa}$ with $5 \% \mathrm{TiB}_{2}$. Therefore, it reached up to $250 \mathrm{MPa}$ for $10 \% \mathrm{TiB}_{2}$. The tensile strength increases by $260 \mathrm{MPa}$ at $15 \% \mathrm{TiB}_{2}$. The percentage is due to the improved linkage between the matrix $\mathrm{TiB}_{2}$ and $\mathrm{Al} 7075$. The results show the $\mathrm{TiB}_{2}$ particles can increase the tensile stress level, but it may 


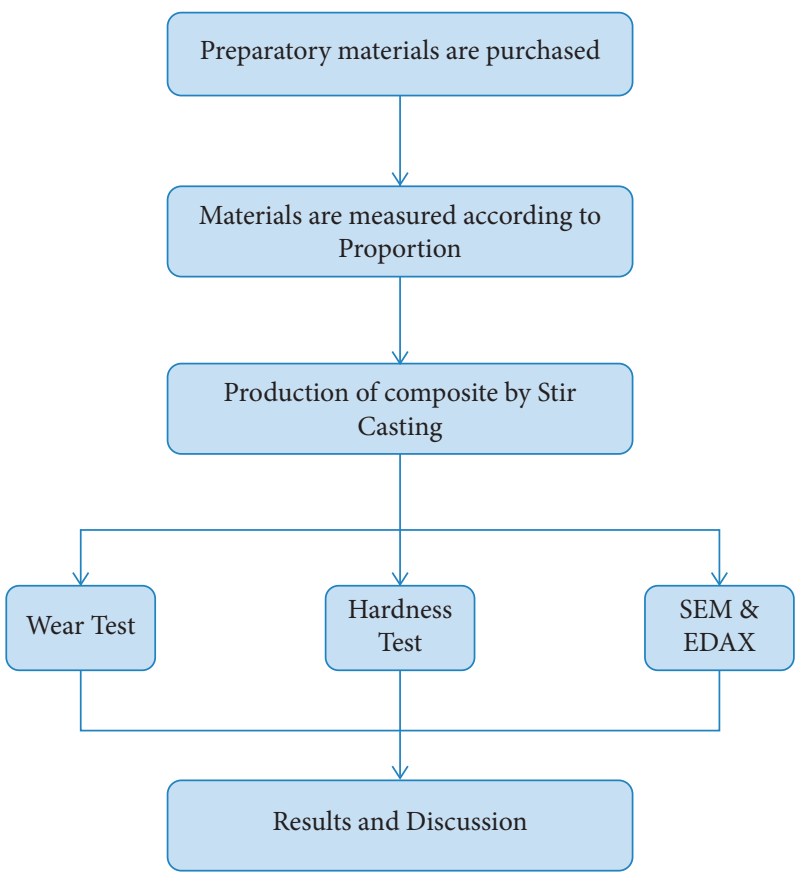

FIgURe 3: Processing methodology.

TABle 2: Sample preparation.

\begin{tabular}{lccc}
\hline Sample no. & Contribution & Aluminium $(\mathrm{g})$ & $\mathrm{TiB}(\mathrm{g})$ \\
\hline 1 & $\mathrm{Al} 707595 \%$ and $\mathrm{TiB}_{2} 5 \%$ & 120.73 & 10.22 \\
2 & $\mathrm{Al} 707590 \%$ and $\mathrm{TiB}_{2} 10 \%$ & 114.38 & 20.44 \\
3 & $\mathrm{Al} 707585 \%$ and $\mathrm{TiB}_{2} 15 \%$ & 108.02 & 30.66 \\
\hline
\end{tabular}

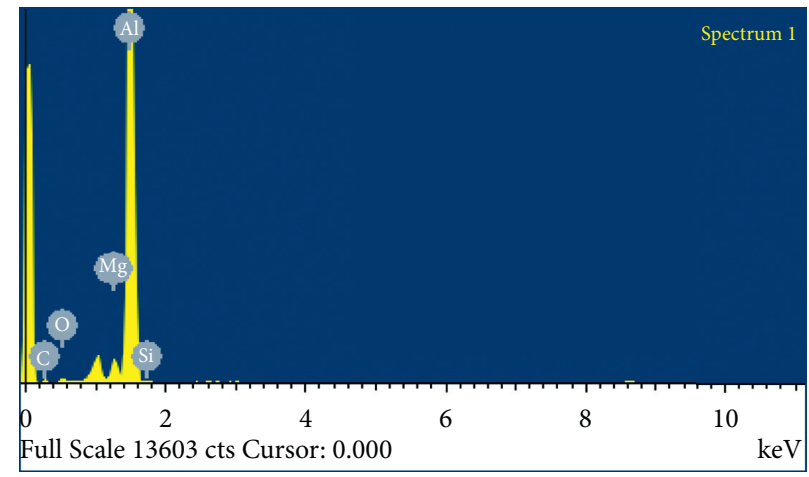

Figure 4: EDAX graph of $\mathrm{Al} 707595 \%$ and $\mathrm{TiB}_{2} 5 \%$.

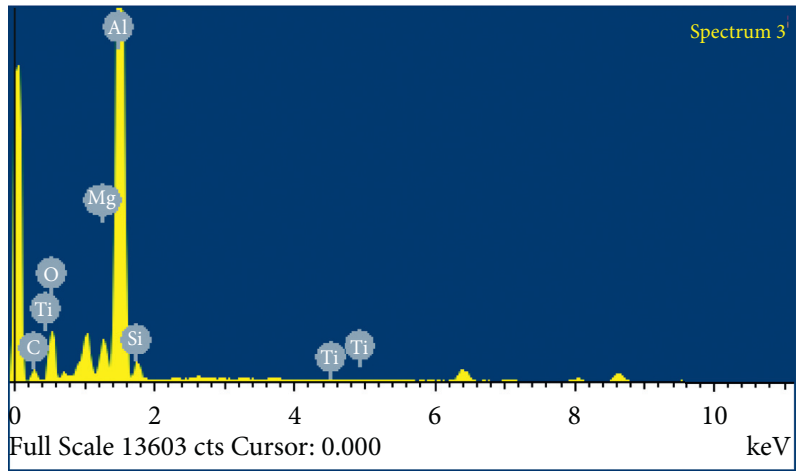

Figure 5: EDAX graph of Al7075 90\% and $\mathrm{TiB}_{2} 10 \%$. 


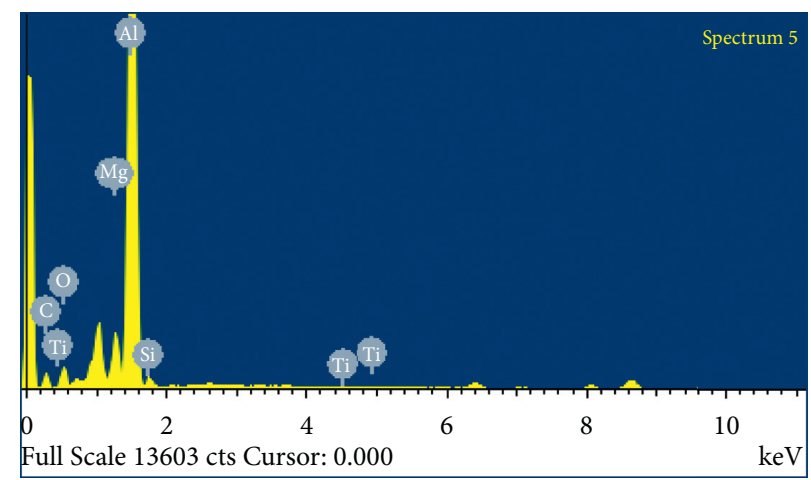

Figure 6: EDAX graph of Al7075 85\% and $\mathrm{TiB}_{2} 15 \%$.

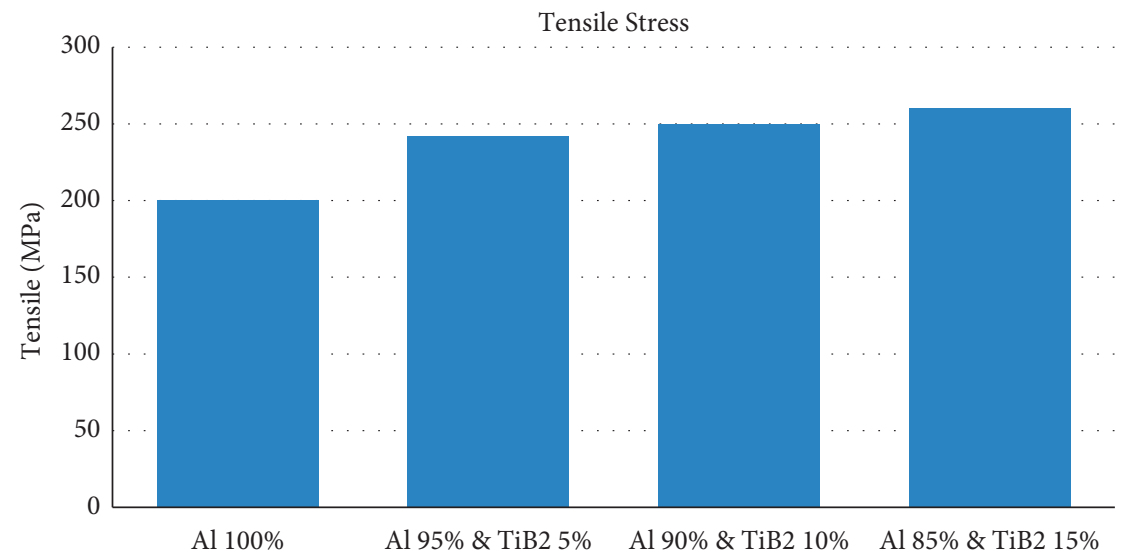

Figure 7: Tensile test report.

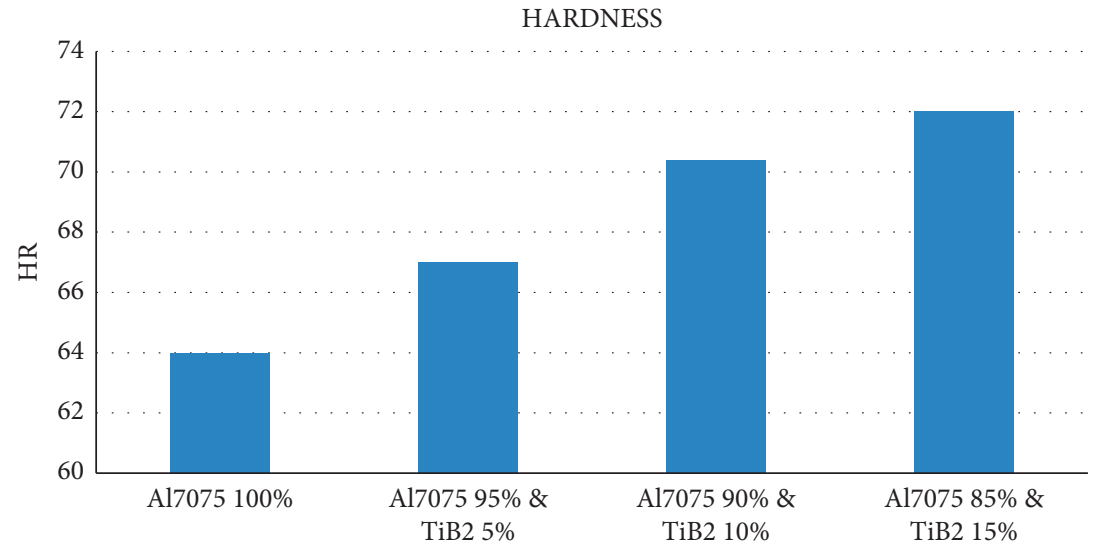

HARDNESS

Figure 8: Hardness value report.

affect the ductile-brittle nature of the composite. Based on the problem mentioned above in this research, the $\mathrm{TiB}_{2}$ was added at the range of $5 \%$ to $15 \%$.

3.3. Impact of Reinforcement on Hardness. In general, hardness is defined as the resistance to indentation. Figure 8 depicts the $\mathrm{Al} 7075$ and $\mathrm{TiB}_{2}$ composites. Figure 8 indicates a major change in the prepared sample's microhardness values was an increase in $5 \% \mathrm{TiB}_{2}, 10 \% \mathrm{TiB}_{2}$, and $15 \% \mathrm{TiB}_{2}$. Table 3 shows the comparison of the pure Al7075 series and the hardness values such as Rockwell hardness number (RHN) enhanced with prepared samples.

$\mathrm{TiB}_{2}$ particles are more resistant to plastic deformation due to the Al7075 matrix; when integrated into the molten matrix, the $\mathrm{TiB}_{2}$ type preferred heterogeneous grain 
TABLE 3: Hardness value for prepared samples.

\begin{tabular}{|c|c|c|c|c|c|c|c|c|c|}
\hline \multirow{2}{*}{ S. no } & \multirow{2}{*}{ Specimen } & \multirow{2}{*}{ Intender } & \multirow{2}{*}{ Load (kgf) } & \multicolumn{5}{|c|}{ Rockwell hardness (HR) } & \multirow{2}{*}{ Mean } \\
\hline & & & & A & $\mathrm{B}$ & $\mathrm{C}$ & $\mathrm{D}$ & E & \\
\hline 1 & Al7075 100\% & Ball & 100 & B64 & B64 & B65 & B63 & B64 & B64 \\
\hline 2 & Al7075 95\% and $\mathrm{TiB}_{2} 5 \%$ & Ball & 100 & B65 & B66 & B70 & B68 & B66 & B67 \\
\hline 3 & $\mathrm{Al} 707590 \%$ and $\mathrm{TiB}_{2} 10 \%$ & Ball & 100 & B69 & B68 & B72 & B73 & B70 & B70.4 \\
\hline 4 & Al7075 $85 \%$ and $\mathrm{TiB}_{2} 15 \%$ & Ball & 100 & B70 & B70 & B73 & B71 & B75 & $\mathrm{B} 72$ \\
\hline
\end{tabular}
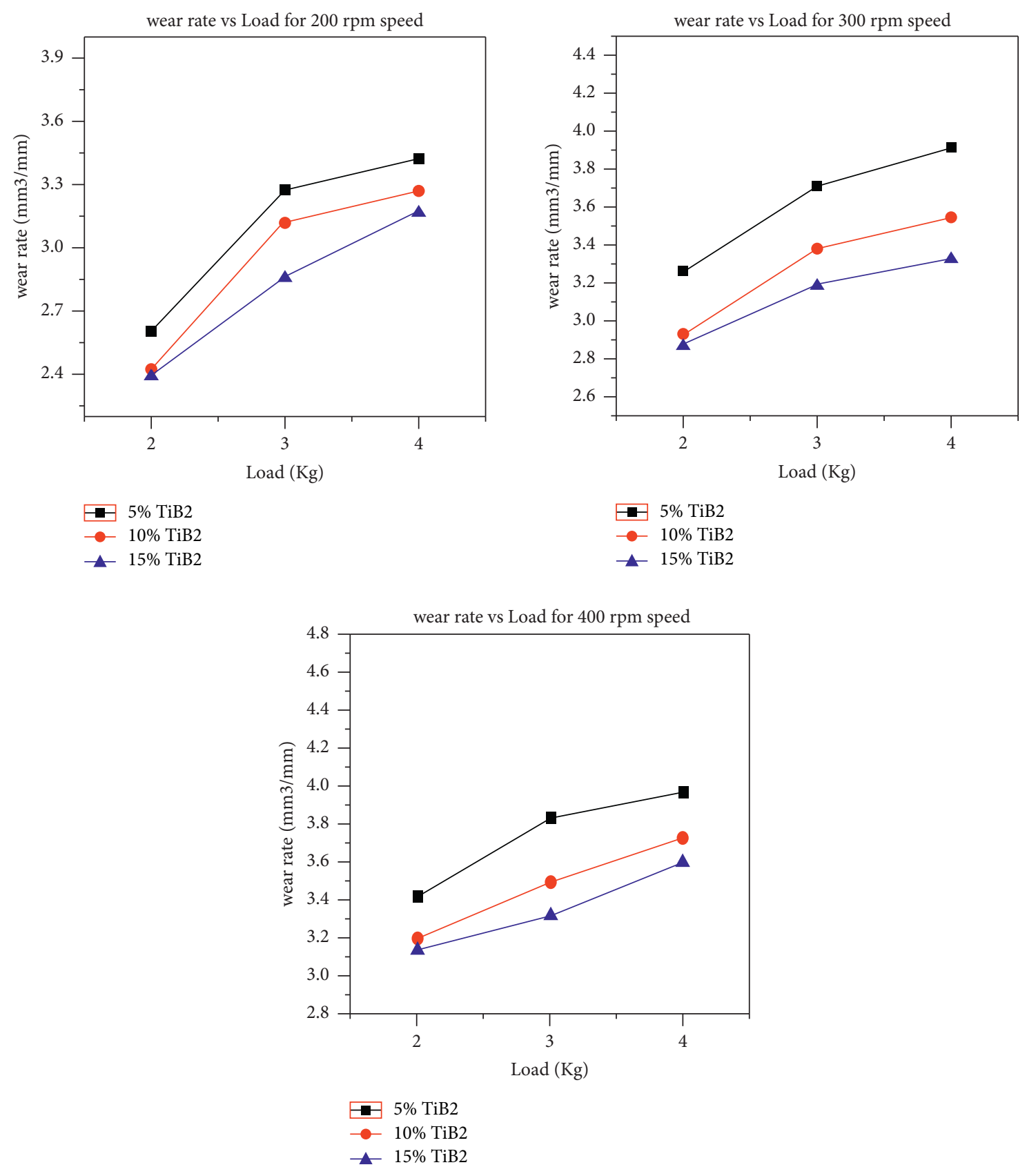

FIGURE 9: Wear rate load.

nucleation sites. Similarly, many researchers reported improving the value of Vickers hardness when $\mathrm{TiB}_{2}$ particles were added to a metallic matrix in situ process [14].
3.4. Impact of Reinforcement on Wear Properties. As a function of the $\mathrm{TiB}_{2}$ weight percentage, load, and speed, Figure 9 indicates Al7075 composite wear. Table 4 shows the wear rate at a constant sliding speed of different percentages 
TABLE 4: Wear rate for prepared samples.

\begin{tabular}{|c|c|c|c|c|}
\hline \multirow{2}{*}{ Speed (rpm) } & \multirow{2}{*}{ Load $(\mathrm{kg})$} & \multicolumn{3}{|c|}{ Wear rate $\left(\mathrm{mm}^{3} / \mathrm{min}\right)$} \\
\hline & & $5 \%$ & $10 \%$ & $15 \%$ \\
\hline \multirow{3}{*}{200} & 2 & 2.61 & 2.42 & 2.4 \\
\hline & 3 & 3.28 & 3.12 & 2.86 \\
\hline & 4 & 3.43 & 3.27 & 3.17 \\
\hline \multirow{3}{*}{300} & 2 & 3.27 & 2.93 & 2.87 \\
\hline & 3 & 3.72 & 3.38 & 3.19 \\
\hline & 4 & 3.92 & 3.55 & 3.33 \\
\hline \multirow{3}{*}{400} & 2 & 3.42 & 3.19 & 3.13 \\
\hline & 3 & 3.84 & 3.49 & 3.31 \\
\hline & 4 & 3.97 & 3.72 & 3.59 \\
\hline
\end{tabular}

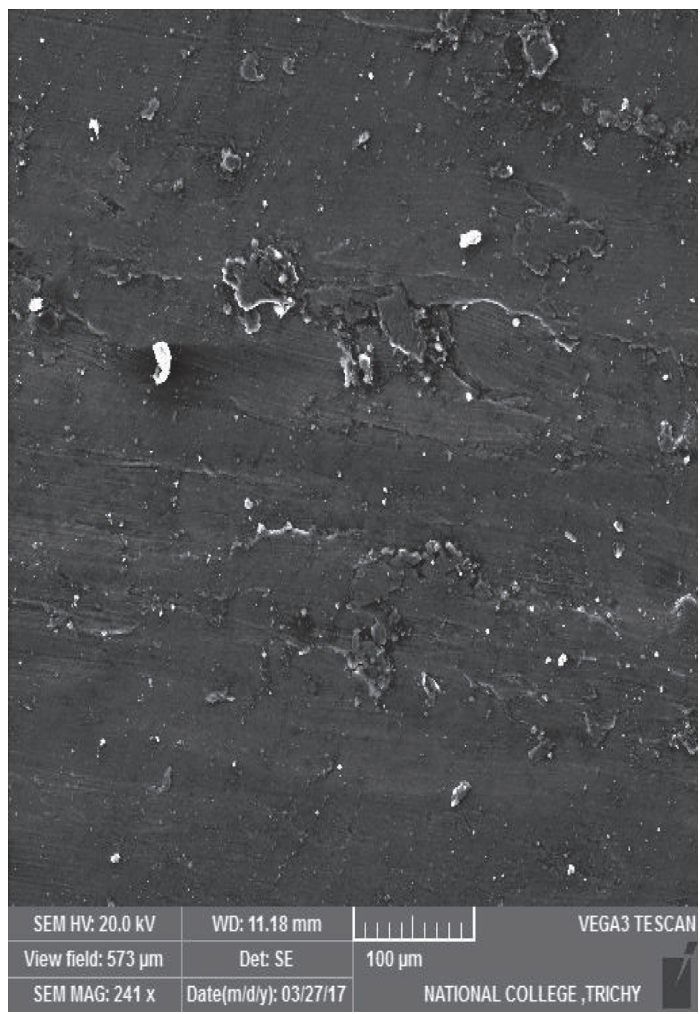

Figure 10: SEM image of Al7075 95\% and $\mathrm{TiB}_{2} 5 \%$.

of $\mathrm{TiB}_{2}$ refurbishments in the Al7075 matrix; therefore, the wear rate generally increases with the rising load. The wear loss of pure Al 7075 alloy is greater than that of other composites. When the amount of $\mathrm{TiB}_{2}$ reinforcements in the Al7075 matrix was increased, the wear rate values began to drop. For all sliding speeds, the same trend was observed as shown in Table 4 . As seen on the base alloy diagram, the wear rate gap is $30-35 \%$, and the inclusion of both loads is $15 \%$ $\mathrm{TiB}_{2}$.

The graph of wear rates is not aligned with the increase in $\mathrm{TiB}_{2}$ strengthening due to the diverse wearing processes as shown in Figure 9. The wear rate at various loads at $200 \mathrm{rpm}$ shows lower wear than that at the higher load. The wear rate is influenced by the reinforcement between the counterfeit and matrix. The adhesive phenomena are produced by contact asperity between the hard face (disk) and the soft surface (pin).
Such touch is deformed by the effects of cold welding and is called adherence. This process leads to a loss of metal as sliding removes asperities from the surface, called adhesive wear. This is based on the applied load function, and $\mathrm{TiB}_{2}$ particles have a constant sliding speed for 20 minutes.

Figure 9 indicates that the effect of $\mathrm{TiB}_{2}$ on wear resistance at lower loads is high, and the wear resistance decreases as the load applied increases to $4 \mathrm{~kg}$. The resulting graph is not linear, as improvements in adhesion and processing characteristics affect composite wear resistance.

As specified in the Archard wear equation act, "hardness is directly proportionate to the composite's volumetric wear resistance" [15]. The $\mathrm{TiB}_{2} \%$ was similar, with a substantial increase in the applied load of $2 \mathrm{~kg}$, but the resistance fell to $3 \mathrm{~kg}$. Due to their major changes in intensity, the proportion of particulate strengthening $\mathrm{TiB}_{2}$ is important to wear study. 


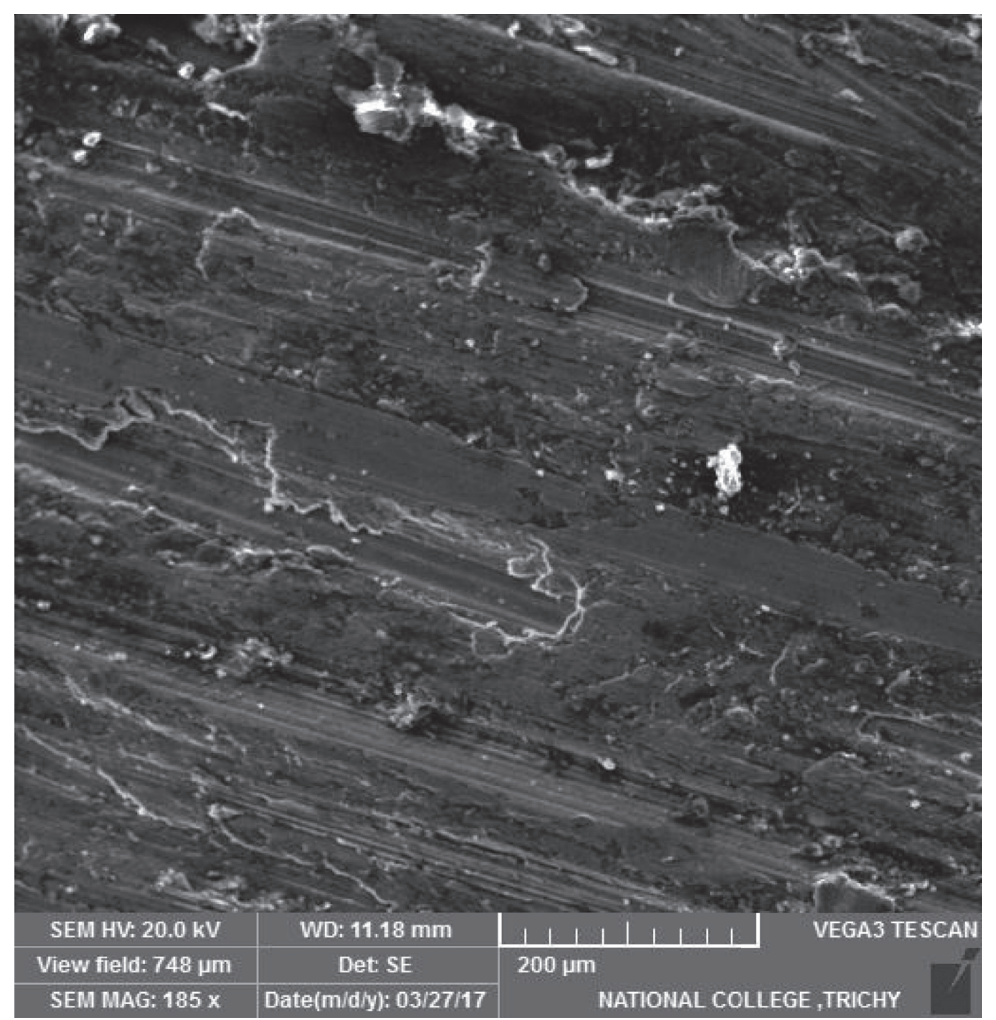

Figure 11: SEM image of Al7075 90\% and $\mathrm{TiB}_{2} 10 \%$.

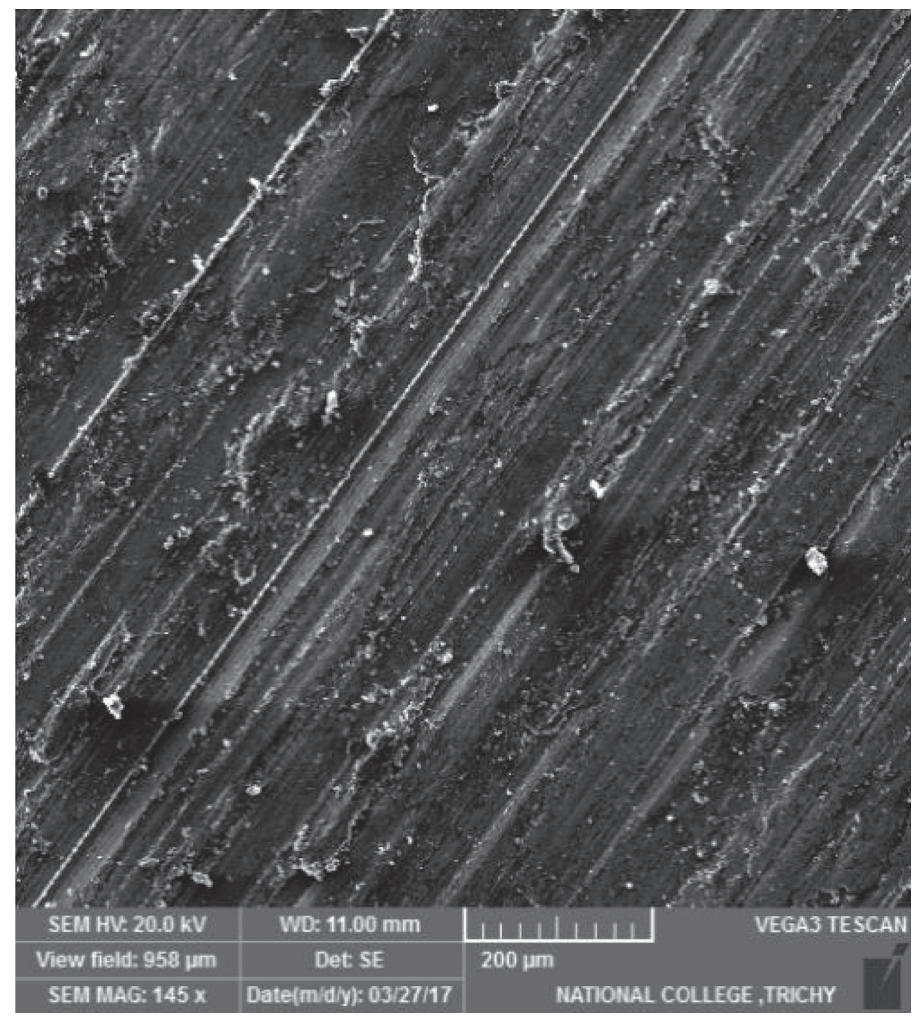

FIgURE 12: SEM image of Al7075 85\% and $\mathrm{TiB}_{2} 15 \%$. 
An analysis of the worn surface and surface morphology is important to better understand the nonlinear graphs found in these specimens.

Figure 10 to 12 show the SEM image of the $\mathrm{TiB}_{2}$ strengthened alliance Al7075 worn base, the specimen samples. The samples are fed on the different 2, 3, and $4 \mathrm{~kg}$ loads at room temperature. At first, chemical acetone was used to clean up the specimens and remove loose particles and dirt $[16,17]$. The wear mechanism demonstrates the plastic surface's deformation due to relative contact motion, tension, asperities, and floor projections.

The wear rate inspection indicates that the grooves, scales, asperities, and ridges run in the sliding direction on the surface in parallel, as shown in Figure 12. The aggression of the grooves grows as the functional factor increases, becoming higher and lower than the regular arming grooves created on the low TiB2 strengthening matrix, which are greater than the $15 \% \mathrm{TiB}_{2}$ adding grooves. The vicinity of wear paths of a thin oxide film indicates the oxide waste surface layers [18]. The large craters were formed in the specimen, and the $\mathrm{TiB}_{2}$ reinforcement particles adhered to the greater scrap due to the sliding conditions of larger scrap.

\section{Conclusion}

The stirring process was carried out with different percentages of $\mathrm{TiB}_{2}$ enhancements applied to Al7075. The tensile stress, hardness range, and tribological characteristics were investigated in this research work; based on the investigation, the following findings have been reported:

(1) Upon melting, the preheating of the $\mathrm{TiB}_{2}$ particles has a significant effect. The porosity is that indicating that the bonding is much better.

(2) When the inclusion of $\mathrm{TiB}_{2}$ particles in the Al7075 matrix increases, microhardness values increase.

(3) The $2 \mathrm{~kg}$ load and $200 \mathrm{rpm}$ sample processing with additional reinforcement of $15 \%$ at a rate of $200 \mathrm{rpm}$ ensure optimum resistance to wear and minimum wear.

(4) Adding $15 \%$ of $\mathrm{TiB}_{2}$ with Al7075 leads to an increase in wear behavior.

(5) In the tribological view, the high load sliding distance and reinforcement percentage of $\mathrm{TiB}_{2}$ increase the wear rate.

\section{Data Availability}

No data were used to support this study.

\section{Conflicts of Interest}

The authors declare that they have no conflicts of interest.

\section{References}

[1] N. C. Kaushik and R. N. Rao, "High-stress abrasive wear behavior of $\mathrm{Al}-\mathrm{Mg}-\mathrm{Si}$ hybrid composites using regression analysis," Industrial Lubrication \& Tribology, vol. 39, 2017.
[2] N. C. Kaushik and R. N. Rao, "Effect of applied load and grit size on wear coefficients of $\mathrm{Al}$ 6082-SiC-Gr hybrid composites under two body abrasion," Tribology International, vol. 103, pp. 298-308, 2016.

[3] N. C. Kaushik and R. N. Rao, "Effect of grit size on two body abrasive wear of $\mathrm{Al} 6082$ hybrid composites produced by stir casting method," Tribology International, vol. 102, pp. 52-60, 2016.

[4] A. Atrian, G. H. Majzoobi, M. H. Enayati, and H. Bakhtiari, "A comparative study on hot dynamic compaction and quasistatic hot pressing of Al7075/SiCnp nanocomposite," Advanced Powder Technology, vol. 26, no. 1, pp. 73-82, 2015.

[5] M. Karbalaei Akbari, H. R. Baharvandi, and O. Mirzaee, "Nano-sized aluminum oxide reinforced commercial casting A356 alloy matrix: evaluation of hardness, wear resistance and compressive strength focusing on particle distribution in aluminum matrix," Composites Part B: Engineering, vol. 52, pp. $262-268,2013$.

[6] A. Kareem, J. A. Qudeiri, A. Abdudeen, T. Ahammed, and A. Ziout, "A review on AA 6061 metal matrix composites produced by stir casting," Materials, vol. 14, no. 1, Article ID 175, 2021.

[7] P. Raghuvaran, M. Suresh, J. Baskaran, S. Arun Prasadh, M. K. Charan, and T. Dhananjayan, "Investigation on characteristics of stir-casted aluminum matrix composites-a review," Springer Proceedings in Materials, vol. 5, pp. 841-851, 2021.

[8] Y. Pazhouhanfar and B. Eghbali, "Microstructural characterization and mechanical properties of TiB2 reinforced Al6061 matrix composites produced using stir casting process," Materials Science and Engineering A, vol. 710, pp. 172-180, 2018.

[9] J. Sundaram, J. Udaya Prakash, and H. Kagitha, "Wear properties on AA2014/Al2O3/TiB2 hybrid metal matrix composites," in Innovative Design, Analysis and Development Practices in Aerospace and Automotive Engineering, pp. 389395, Springer, Berlin, Germany, 2021.

[10] D. Jianxin, A. Xing, and L. Zhaoqian, "Friction and wear behavior of $\mathrm{Al} 2 \mathrm{O} 3 / \mathrm{TiB} 2$ composite against cemented carbide in various atmospheres at elevated temperature," Wear, vol. 195, no. 1-2, pp. 128-132, 1996.

[11] D. Jianxin and A. Xing, "SiC whisker reinforced Al2O3/TiB2 ceramic composites," Chinese Ceramic Society, vol. 23, no. 4, pp. 385-392, 1995.

[12] J. Hashim, L. Looney, and M. S. J. Hashmi, "Metal matrix composites: production by the stir casting method," Journal of Materials Processing Technology, vol. 92-93, pp. 1-7, 1999.

[13] Y. Han, X. Liu, and X. Bian, "In situ TiB2 particulate reinforced near eutectic Al-Si alloy composites," Composites Part A: Applied Science and Manufacturing, vol. 33, no. 3, pp. 439-444, 2002.

[14] S. Natarajan, R. Narayanasamy, S. P. Kumaresh Babu, G. Dinesh, B. Anil Kumar, and K. Sivaprasad, "Sliding wear behaviour of $\mathrm{Al} \mathrm{6063/TiB2}$ in situ composites at elevated temperatures," Materials \& Design, vol. 30, no. 7, pp. 2521-2531, 2009.

[15] A. Mandal, B. S. Murty, and M. Chakraborty, "Sliding wear behaviour of T6 treated A356-TiB2 in-situ composites," Wear, vol. 266, no. 7-8, pp. 865-872, 2009.

[16] A. Mandal, M. Chakraborty, and B. S. Murty, "Effect of TiB2 particles on sliding wear behaviour of $\mathrm{Al}-4 \mathrm{Cu}$ alloy," Wear, vol. 262, no. 1-2, pp. 160-166, 2007.

[17] A. Haiter Lenin, S. C. Vettivel, T. Raja, L. Belay, and S. C. E. Singh, "A statistical prediction on wear and friction 
behavior of $\mathrm{ZrC}$ nano particles reinforced with $\mathrm{Al} \mathrm{Si}$ composites using full factorial design," Surfaces and Interfaces, vol. 10, pp. 149-161, 2018.

[18] G. Robert Singh, S. Christopher Ezhil, M. Sivapragash, L. Anselm, R. S. Kumar, and A. Haiter Lenin, Tensile and compression behaviour, microstructural characterization on Mg-3Zn-3Sn-0.7Mn alloy reinforced with SiCp prepared through powder metallurgy method," Materials Research Express, vol. 9, 2020. 